\title{
ASSESSING AND MODELING PARTICULATE POLLUTION IN THE CITY OF OUAGADOUGOU (BURKINA FASO)
}

\author{
Ouarma Issoufou ${ }^{1, ~ *}$, Nana Bernard ${ }^{2}$, Haro Kayaba ${ }^{1,3}$, Koulidiati Jean ${ }^{1}$, and Béré Antoine ${ }^{1}$ \\ ${ }^{1}$ Laboratoire de Physique et de Chimie de l'Environnement, Université Joseph KI-ZERBO, Ouagadougou, Burkina Faso \\ ${ }^{2}$ Institut Des Sciences, Ouagadougou, Burkina Faso \\ ${ }^{3}$ Institut de Recherche en Sciences Appliquées et Technologie, Centre National de la Recherche Scientifique et \\ Technologique, Ouagadougou, Burkina Faso \\ *ouarma.issoufou@hotmail.fr
}

\section{INFOS SUR L'A R T I C L E}

Historique de l'article :

Reçu le : 24 novembre 2020

Reçu en format révisé le : 09 février 2021

Accepté le : 02 mars 2021

Keywords : Particulate pollution ; $P M_{2.5}$; PM 10 ; AEROCET; MUNICH ; COPERT IV, US EPA AP 42, Modeling

Mots-Clés : Pollution particulaire ; $P M_{2.5}$; PM 10 ; AEROCET ; MUNICH ; COPERT IV AP 42 US EPA, Modélisation

\begin{abstract}
A B S T R A C T
In the present work, the pollution levels of airborne particles in the city of Ouagadougou have been assessed through two campaigns of in situ measurements of $\mathrm{PM}_{2.5}$ and $\mathrm{PM}_{10}$ concentrations. These measures were performed using a portable device (AEROCET 531S) on roadside sites and on sites located in administrative services, secondary schools and outlying districts. Since in situ measurements don't give any indication of the pollution that could be due to a new source (industrial plant, road, etc.) and how it is dispersed spatially and temporally, thus pollutant emissions from road traffic and the dispersion of these pollutants are obtained by a modelling chain that couples COPERT IV emission model under Pollemission code with MUNICH dispersion model. As results, the average 24-hour concentrations are $87 \pm 16$ and $951 \pm 266 \mu \mathrm{g} / \mathrm{m}^{3}$ for the $\mathrm{PM}_{2.5}$ and $\mathrm{PM}_{10}$, respectively, in 2018 dry season. They are $29 \pm 5$ and $158 \pm 43 \mu \mathrm{g} / \mathrm{m}^{3}$, respectively, in 2018 rainy season and, $22 \pm 9$ and $187 \pm 67 \mu \mathrm{g} / \mathrm{m}^{3}$ in 2019 rainy season, respectively. These results show that independently of the season (dry or rainy), the $\mathrm{PM}_{10}$ concentrations are high and exceed the World Health Organization Air Quality Guidelines (WHO AQG) and European 24-hour threshold value of $50 \mu \mathrm{g} / \mathrm{m}^{3}$. Concerning the $\mathrm{PM}_{2.5}$ concentrations in dry season, they are high and exceed the WHO AQG and European 24-hour threshold value of $25 \mu \mathrm{g} / \mathrm{m}^{3}$. The results obtained concerning the modeling of the dispersion of PM air pollution due to road traffic in the city of Ouagadougou are partially satisfactory. The modeled maximum values of the exhaust emission factors are very high while the modeled concentrations are underestimated compared to the measured concentrations The estimated emission factors range between 0 and $400 \mathrm{~g} / \mathrm{km} / \mathrm{h}$ and between 0 and $303 \mathrm{~g} / \mathrm{km} / \mathrm{h}$ for exhaust $\mathrm{PM}_{2.5}$ and resuspension $\mathrm{PM}_{2.5}$, respectively. They vary between 0 and $2997 \mathrm{~g} / \mathrm{km} / \mathrm{h}$ for resuspension $\mathrm{PM}_{10}$. Concerning the modelled concentrations, they are between 0 and $238 \mu \mathrm{g} / \mathrm{m}^{3}$ for $\mathrm{PM}_{2.5}$ and between 0 and $2072 \mu \mathrm{g} / \mathrm{m}^{3}$ for $\mathrm{PM}_{10}$. These results can be improved with updated traffic and road characterization data.
\end{abstract}

\section{INTRODUCTION}

Among air pollutants, particulate matter (PM) is recognized as the most important that have effects on human health including cardio-respiratory pathologies, acute bronchopneumonia, lung cancer, etc. In sub-Saharan Africa countries, particularly in Burkina Faso, there is very few research works on air pollution assessing (Nana et al., 2019; Ndong et al., 2019).

The term "particulate" in particulate matter is a generic term that refers to a mixture of solid and/or liquid pollutants suspended in a gaseous medium (Airparif, 2008). These particles are also referred to as aerosols, a term that includes both the particles and the gas in which they are suspended. The size of these particles can range from a few order of micrometers $(3-10 \mu \mathrm{m})$ to a hundred micrometers $(100 \mu \mathrm{m})$. From a chemical point of view, aerosols are aggregates of molecules present in the atmosphere that have agglutinated together as a result of a process called "nucleation". Several million tons of aerosols are emitted per day into the atmosphere from a wide variety of sources (MEDDT, 2010). The composition and size distribution of PM is highly dependent on its formation processes, i.e. the sources of the particles, and this has been explored in numerous studies (Tsai et al., 2015). 
Studies of European cohort on the effects of air pollution have shown that particulate matter (PM) of diameter less than $10 \mu \mathrm{m}\left(\mathrm{PM}_{10}\right)$ and $2.5 \mu \mathrm{m}\left(\mathrm{PM}_{2.5}\right)$ are associated with a risk of developing lung cancer (Raaschou-Nielsen et al., 2013). Nowadays, PM in outdoor air as carcinogenic to human (Loomis et al., 2013).

The main purpose of this work is to assess the PM pollution levels and their dispersion in Ouagadougou through in-situ measurements and modeling. As far as the measurement sites are concerned, some of them were selected on the basis of previous work on air pollution in the city of Ouagadougou carried out in 2006 and 2007. The most recent in situ measurement work on this subject has not only covered fewer sites but is more than 10 years old (Lindén et al., 2012; Nana et al., 2012). As regards air pollution modelling in the city of Ouagadougou, the present work is one of the first attempts to model particulate pollution. Similar previous work such as that of Tractebel et al (1999) estimated gaseous (not particulate) emissions using a mathematical traffic and air quality impact model. Hence the originality of the present work, which focused on particulate pollutants in the city of Ouagadougou.

\section{MATERIAL AND METHODS}

\subsection{Experimental site}

Air pollutant measurement campaigns concerned ten (10) sites throughout the city of Ouagadougou (figure 1). Other sites were selected to have a sample that better characterizes Ouagadougou and its environment. These sites are classified as: (i) school sites located in secondary schools (C3 and H6), (ii) peripheral district sites located in suburban areas with heavy traffic on unpaved roads (Kar and BV), (iii) industrial sites located in the industrial zone of Kossodo (IRSAT and ZIK), (iv) traffic sites located along paved roads (BCDG and $\mathrm{AB}$ ) and (v) administrative sites (E7 and UJKZ) located in administrative or similar services.

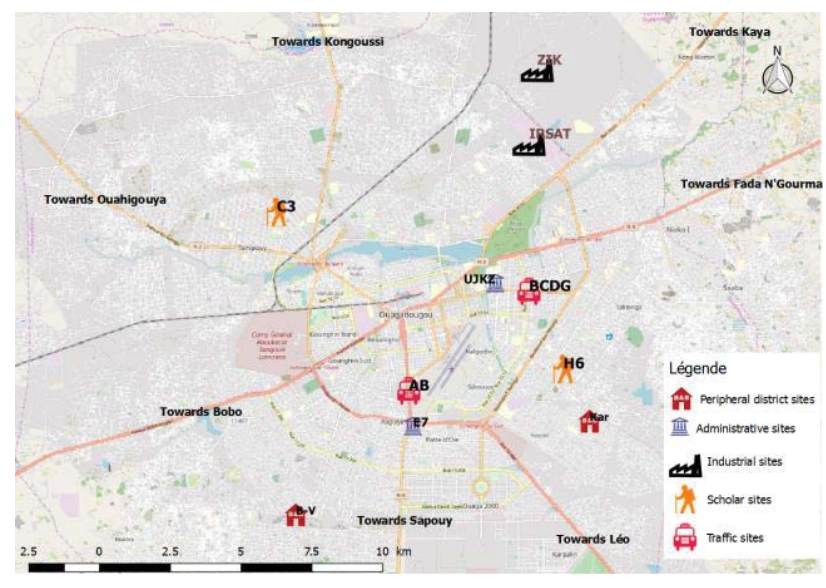

Figure 1. Location of measurement sites for particle pollutants in the city of Ouagadougou

\subsection{Materials}

A portable analyzer (Figure 2), called AEROCET 531S, was used for in-situ measurements because it is the device available in our laboratory to carry out measurements of particulate pollutants. It consists of a mass profiler and a particle counter combined in a small portable battery-powered unit. The analyzer measures particles with a diameter between 0.3 and $10.0 \mu \mathrm{m}$ and some others (total suspended particles). Its detection limit is $1.0 \mu \mathrm{g} / \mathrm{m}^{3}$. Measures were carried out in dry season 2018 and in rainy season 2018 and 2019.

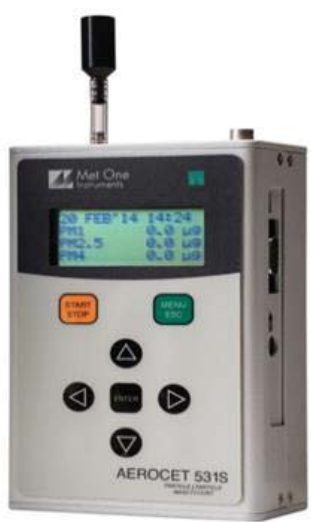

Figure 2: AEROCET $531 S$ with its isokinetic sampling probe

\subsection{Modeling}

Modeling the dispersion of air pollution in Ouagadougou aims at estimating, at the scale of the city of Ouagadougou and at a temporal resolution of the order of a minute, on the one hand, the emissions of pollutants due to road traffic and, on the other hand, the dispersion of these pollutants throughout the city.

Figure 3 displays the road traffic air pollution dispersion modeling framework.

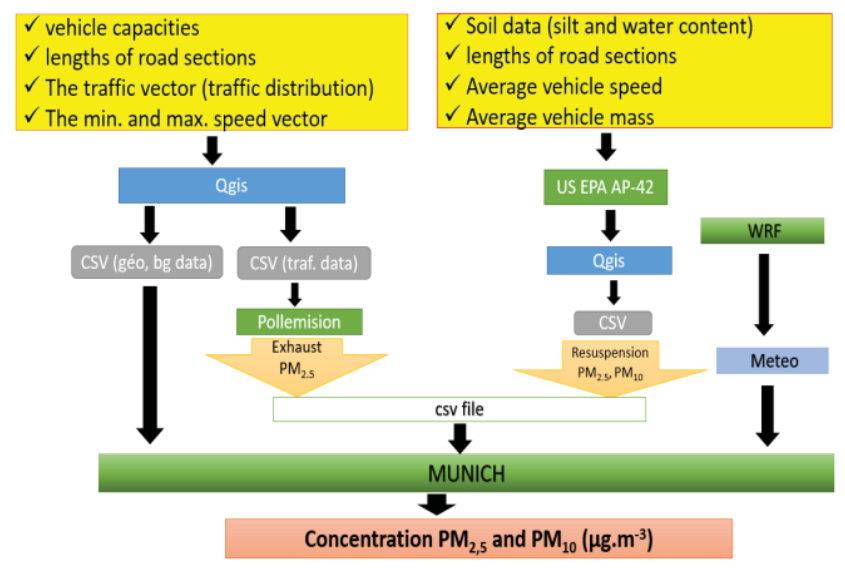

Figure 3. Air pollution modelling chain: CSV (Comma separated values) is a spreadsheet that contains the input data for the numerical models. Qgis, formerly known as Quantum GIS, is a free, open-source Geographic Information System (GIS) application for visualizing, modifying and analyzing geospatial data) 
First, the calculation of exhaust particulate matter (PM) emissions due to traffic at street level is carried out through an open source code named Pollemission (Chen and Mallet, 2016). It should be noted that the original Pollemission code only calculates emission factors for passenger vehicles. In the case of the city of Ouagadougou, where motorized two-wheelers (2WD) predominate, a specific code in Python language was written and integrated into Pollemission. Then, the calculation of particulate pollutant emissions due to dust resuspension is performed by the US-EPA AP 42 model (US EPA, 2011). Finally, the calculation of the dispersion of these air pollutants due to road traffic is performed through an open source code, MUNICH (Kim et al., 2018). The models were chosen because they take into account the data from the study site, i.e. the characteristics of the road surface materials and traffic.

The values of Pollemission input parameters were derived from the inventory of air pollutant emissions from road traffic in Ouagadougou conducted in 2016 (Somda et al., 2018). The data for the speed vector ( $\mathrm{min}$. and max.) of the vehicles are default values of COPERT IV (Gkatzoflias et al., 2008). The average lengths of the sections are given by OpenStreetMap. The data on silt and water content of the sections were determined by soil sampling and laboratory analysis in accordance with previous work on the characterization of lateritic materials (Ouarma, 2012).

\section{RESULTS AND DISCUSSION}

\subsection{Experimental results}

Our experimental results of PM concentrations hourly profiles in Ouagadougou and their average concentrations have been recently published (Ouarma et al., 2020). The main conclusions are: (1) the evolution curves of PM concentrations hourly profiles show approximately two pollution peaks over a 24-hour period; (2) the average 24hour concentrations are $87 \pm 16$ and $951 \pm 266 \mu \mathrm{g} / \mathrm{m}^{3}$ for the $\mathrm{PM}_{2.5}$ and $\mathrm{PM}_{10}$, respectively, in 2018 dry season. They are $29 \pm 5$ and $158 \pm 43 \mu \mathrm{g} / \mathrm{m}^{3}$, respectively, in 2018 rainy season and, $22 \pm 9$ and $187 \pm 67 \mu \mathrm{g} / \mathrm{m}^{3}$ in 2019 rainy season, respectively. These results show that, independently of the season, the $\mathrm{PM}_{10}$ concentrations are high and exceed the WHO AQG and European 24-hour threshold value of 50 $\mu \mathrm{g} / \mathrm{m}^{3}$. Concerning the $\mathrm{PM}_{2.5}$ concentrations, those measured in dry season are high and exceed the WHO AQG and European 24-hour threshold value of $25 \mu \mathrm{g} / \mathrm{m}^{3}$.

The frequencies or number of times over the 24-hour measurement period that the measured concentrations exceed the threshold value recommended by international institutions (WHO, EEA, US EPA) and Burkina Faso (BFA) were evaluated using descriptive statistics and the results are showed in figure 4. For $\mathrm{PM}_{2.5}$, excepted for school sites, they vary approximatively between $33 \%$ and $50 \%$ for other sites and between 38 and $92 \%$. for $\mathrm{PM}_{10}$. This means that in 24 hours, every person living in the city of Ouagadougou is exposed to pollution of $\mathrm{PM}_{2.5}$ between
8 to 12 hours and to pollution of $\mathrm{PM}_{10}$ between 9 to 22 hours depending on the person residencies (measurement sites). More specifically concerning the concentrations (24h), although the measurements were made during the rainy season, the data show that during the 24 hours, a person living near the BV (Bonheur Ville) site is exposed for 7 hours to $\mathrm{PM}_{2.5}$ air pollution that exceeds the threshold value recommended by the WHO. This exposure duration is $8 \mathrm{~h}, 9 \mathrm{~h}, 10 \mathrm{~h}, 11 \mathrm{~h}$ and 12 respectively for a person living near the site ZIK (Kossodo Industrial Zone), BCDG (Boulevard Charles De Gaulle) and Kar (Karpala), IRSAT, AB (Avenue Bassawarga) and UJKZ (Joseph KI-ZERBO University), and E7 (ONATEL SUD). Similarly, a person in the vicinity of the E7 site (ONATEL SUD), is exposed for 9 hours to $\mathrm{PM}_{10}$ air pollution that exceeds the threshold value recommended by the WHO and between 20 and 23 hours for the other sites. Concerning school sites, H6 (Complexe scolaire Bon Berger) and C3 (Complexe scolaire Notre Dame de l'Espérance)), this average duration is 0 hour for $\mathrm{PM}_{2.5}$ and $1 \mathrm{~h}$ for $\mathrm{PM}_{10}$ and is explained by the fact that the measurements were carried out during school vacations.

The most important exceedance frequencies are observed on traffic sites, peripheral districts and industrial sites due respectively to the importance of traffic on paved roads, traffic on a dense network of unpaved roads and industrial activities. These activities strongly contribute to particulate pollution. The lowest concentrations were measured at school sites where monitoring were performed during the school holiday period.

These results show the need to conduct epidemiological studies to investigate the links between lung diseases and exposure to PM in the city of Ouagadougou, mainly for the $\mathrm{PM}_{10}$.

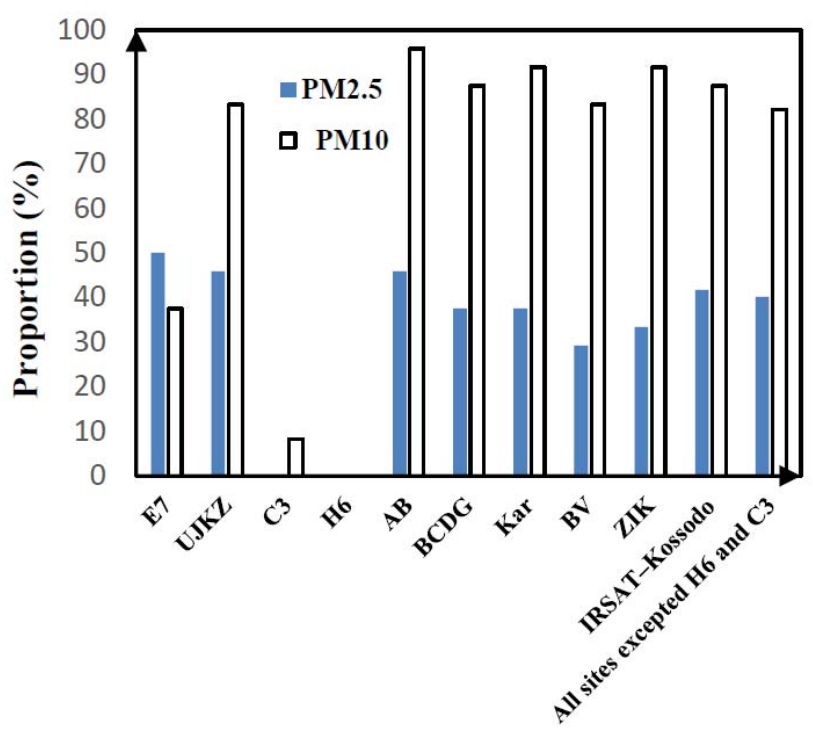

Figure 4. Proportion of measured concentrations exceeding WHO recommended threshold values 


\subsection{Modeling results}

\subsubsection{Exhaust emission Factor}

Exhaust emission factors for PM related to road traffic concern only $\mathrm{PM}_{2.5}$. They are estimated by Pollemission calculations. The calculated values are between 0 and 400 $\mathrm{g} / \mathrm{km} / \mathrm{h}(111 \mathrm{mg} / \mathrm{km})$. The maximum value is about 10 times and 1.2 times higher than the lowest average value $(11.3 \mathrm{mg} / \mathrm{km})$ and the highest average value $(92 \mathrm{mg} / \mathrm{km})$ measured in recent similar works (Abdallah et al., 2020).

Traffic characteristics (average age of vehicles, proportion of heavy trucks and similar vehicles, proportion of diesel vehicles, fuel characteristics, average cumulative distance travelled per vehicle, vehicle maintenance, etc.) essentially explain these differences.

\subsubsection{Resuspension emission factors}

They concern both $\mathrm{PM}_{2.5}$ and $\mathrm{PM}_{10}$ and are given by calculations with US EPA AP-42. The calculated values range from 0 to $303 \mathrm{~g} / \mathrm{km} / \mathrm{h}(84.1 \mathrm{mg} / \mathrm{km})$ for $\mathrm{PM}_{2.5}$ and 0 to $2,997 \mathrm{~g} / \mathrm{km} / \mathrm{h}(833 \mathrm{mg} / \mathrm{km})$ for $\mathrm{PM}_{10}$. The emission factor maps show a correlation between the values obtained and road types (paved and unpaved). Indeed, the highest values are obtained in peripheral districts that are characterized by a significant number of unpaved roads, unlike the downtown area. The characteristics of the surface materials explain these results.

\subsubsection{Emissions}

Emissions of a given type of pollutant represent the total amount of emissions of that pollutant in the entire study area. It is obtained by summing the emissions on each street section in the study area. $\mathrm{PM}_{2.5}$ and $\mathrm{PM}_{10}$ emissions related to road traffic in the city of Ouagadougou are estimated at about 341 and 31,931 t/day respectively. These emissions come mainly from the motorized twowheelers (2WD): about $64 \%$ contribution for $\mathrm{PM}_{2.5}$, and $74 \%$ for $\mathrm{PM}_{10}$. It should be noted that these values are underestimated because the emission factors for some sections are assumed to be zero due to the lack of traffic data.

\subsubsection{PM2.5 dispersion}

The dispersion maps (figures 5 and 6) highlight that the pollution of $\mathrm{PM}_{2.5}$ is mainly related to dust resuspension especially on unpaved roads. Indeed, it appears from the maps that the low concentration values are observed in the city center and on the streets of Ouaga 2000. The maps also show slight variations in concentrations according to the type of reference concentration. For the large majority of the streets, the concentrations are higher than the exposure limit value recommended by the WHO for $\mathrm{PM}_{2.5}$, which is $25 \mu \mathrm{g} / \mathrm{m}^{3}$ for twenty-four (24) hours of continuous exposure.

\subsection{5. $\mathrm{PM}_{10}$ dispersion}

In contrast to $\mathrm{PM}_{2.5}$, the $\mathrm{PM}_{10}$ dispersion maps (figures 7 and 8) do not show high difference behavior between on unpaved and paved roads. Overall, it can be seen that $\mathrm{PM}_{10}$ concentrations increase with the duration of dispersion regardless of the type of reference concentration. The highest concentrations are obtained on unpaved roads. Highly polluted areas are located on the outskirts of the city where the density of unpaved roads is high. The modeled concentrations (24h) for the majority of streets are higher than the WHO AQG and European 24-hour threshold value of $50 \mu \mathrm{g} / \mathrm{m}^{3}$.
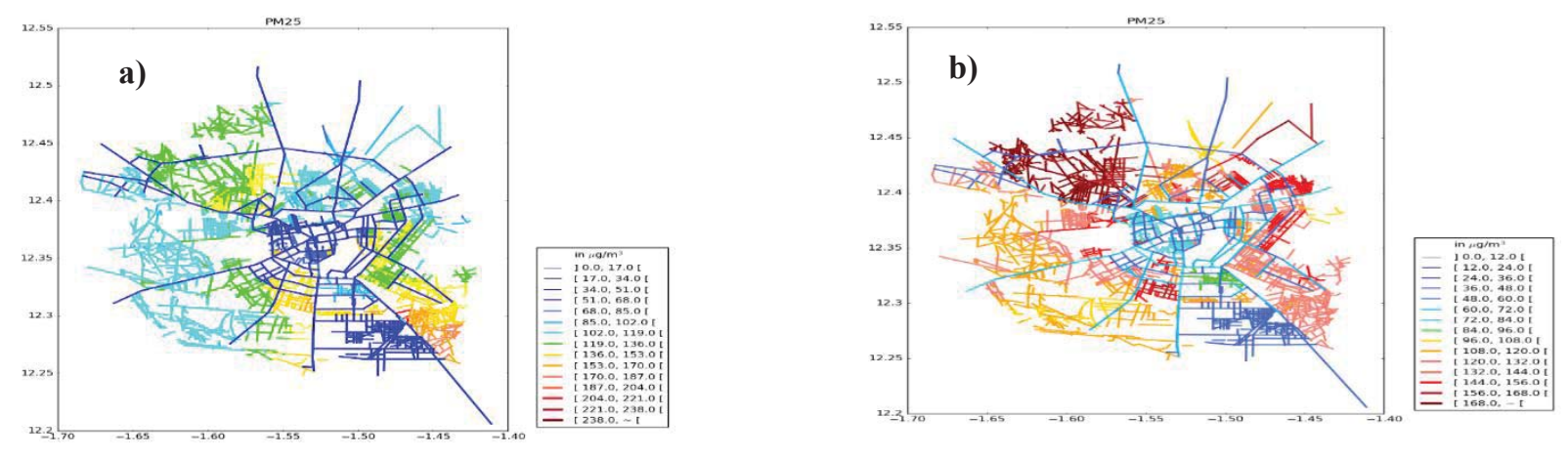

Figure 5. Dispersion maps of PM2.5 emitted by traffic for the average height of roadside buildings at $2.8 m$ and for a dry season type reference concentration. a) in 24 hours per day; b) in 26 days (monthly). 

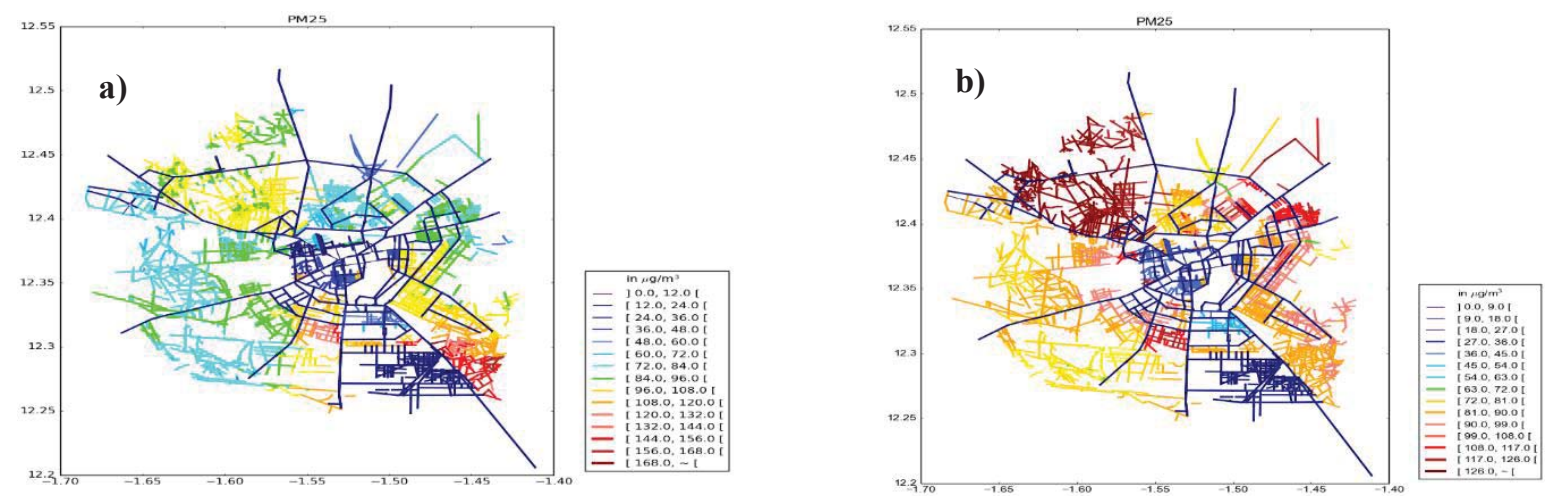

Figure 6. Dispersion maps of $P M_{2.5}$ emitted by traffic for the average height of roadside buildings at $2.8 m$ and for a rainy season reference concentration. a) in 24 hours per day; b) in 26 days (monthly)
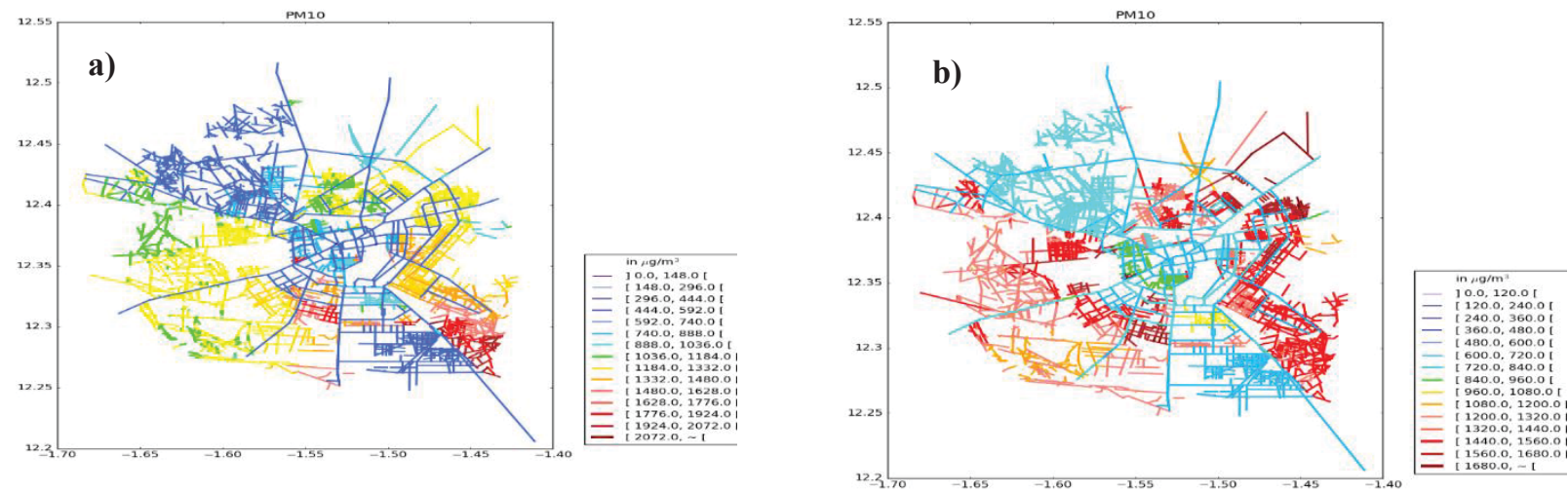

Figure 7. Dispersion maps of PMI0 emitted by traffic for the average height of roadside buildings at $2.8 \mathrm{~m}$ and for a dry season type reference concentration. a) in 24 hours per day; b) in 26 days (monthly)
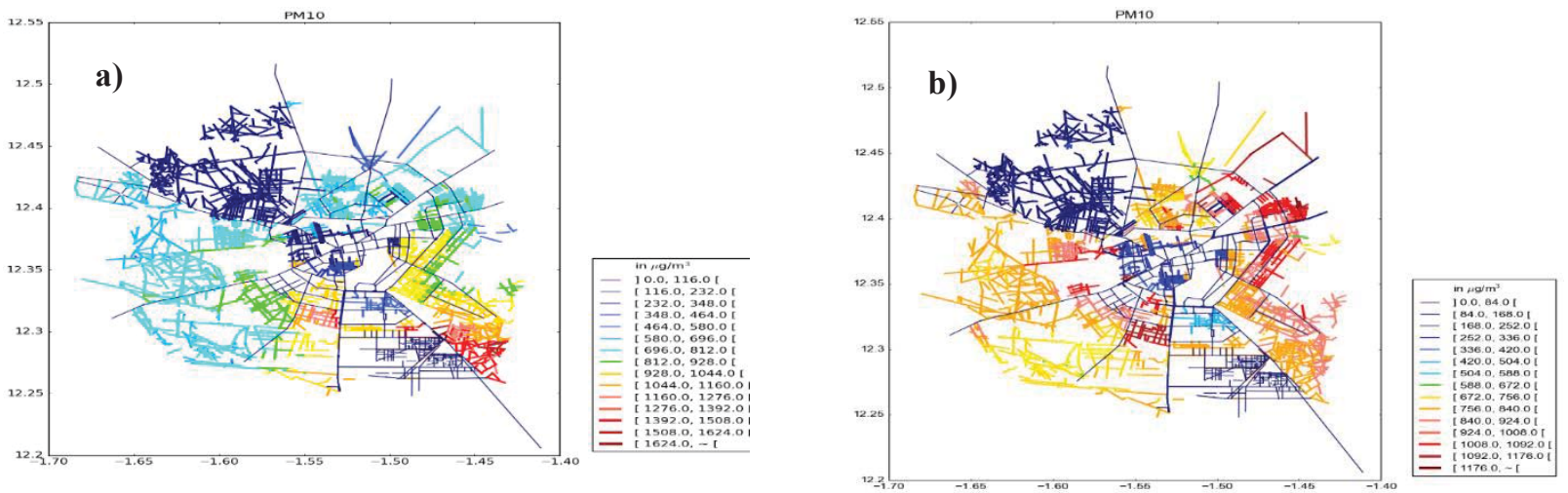

Figure 8. Dispersion maps of PM10 emitted by traffic for the average height of roadside buildings at $2.8 \mathrm{~m}$ and for a rainy season reference concentration. a) in 24 hours per day; b) in 26 days (monthly)

\section{CONCLUSION}

Air pollution in the city of Ouagadougou has been measured and modeled in the present work. For in situ monitoring, an automatic analyzer was used to perform the measurements on each site and for modelling, a computing model for suspended particulate matter, exhaust emissions and dispersion were used.

The measured results show that, independently of the season, the $\mathrm{PM}_{10}$ pollution levels are high and exceed the recommended 24-hour threshold value $\left(50 \mu \mathrm{g} / \mathrm{m}^{3}\right)$. Concerning the $\mathrm{PM}_{2.5}$, pollution levels in dry season are high and exceed the 24-hour threshold value. The dispersion air modelling for the city of Ouagadougou is a first and the obtained results are partially satisfactory. Updated traffic data, road characterization and reference concentrations are necessaries to improve the obtained results. This can be achieved on the one hand by carrying out a road traffic inventory and on the other hand by carrying out large-scale in situ measurements of pollutant concentrations with high-performance automatic analyzers.

\section{REFERENCES}

Abdallah, C., C. Afif, S. Sauvage, A. Borbon, T.

Salameh, A. Kfoury, T. Leonardis, et al., (2020). 
Determination of Gaseous and Particulate Emission Factors from Road Transport in a Middle Eastern Capital. Transportation Research Part D: Transport and Environment 83: 102361.

https://doi.org/10.1016/j.trd.2020.102361

Airparif. (2008). Synthèse des connaissances sur les particules en suspension dans l'air et des travaux d'Airparif sur ces polluants.

Chen, R. et Mallet, V. (2016). Pollemission software computing traffic emissions of atmospheric pollutants with COPERT-IV formulations.

https://github.com/pollemission

Gkatzoflias, D. et al. (2008). Copert 4', Mechanical Engineering. (December 2015).

Kim, Y. et al. (2018). Multi-scale modeling of urban air pollution: Development and application of a Street-inGrid model (v1.0) by coupling MUNICH (v1.0) and Polair3D (v1.8.1). Geoscientific Model Development. Copernicus GmbH. 11(2), pp. 611-629. https://doi.org/10.5194/gmd-11-611-2018

Lindén, J. et al. (2012). Intra-urban air pollution in a rapidly growing Sahelian city. Environment International. 40(1), pp. 51-62. https://doi.org/10.1016/j.envint.2011.11.005

Loomis, D. et al. (2013). The carcinogenicity of outdoor air pollution. The Lancet Oncology. 14(13), pp. 12621263. https://doi.org/10.1016/S1470-2045(13)70487-X.

MEDDTL. (2010). Ministère de l'écologie, du développement durable, des transports et du logement. Opération SERRES - État de l'art des mesures de pollution et de trafic par le capteur laser. Rapport 01. CETE de l'Ouest/Laboratoire Régional des Ponts et Chaussées d'Angers (France).

Nana, B., Sanogo, O, Savadogo, P. W, Daho, T., Bouda, M. and Koulidiati, J. (2012). Air Quality Study in Urban Centers: Case Study of Ouagadougou, Burkina Faso. FUTY Journal of the Environment. 7(1), pp. 118. http://dx.doi.org/10.4314/fje.v7i1.1

Ouarma Issoufou. (2012). Étude des propriétés mécaniques des matériaux de construction : cas des blocs en terre comprimés obtenus avec de la terre latéritique au ciment et de la décoction de néré. Mémoire de D.E.A, UFR-SEA, Université de Ouagadougou (Burkina Faso)

Ouarma, I., Nana, B., Haro, K., Béré, A and Koulidiati, J. (2020). Assessment of pollution levels of suspended particulate matter on an hourly and a daily time scale in West African cities: case study of Ouagadougou (Burkina Faso). Journal of Geoscience and Environmental Protection. 8(11), pp 119-138. https://doi.org/10.4236/gep.2020.811007
Raaschou-Nielsen, O. et al. (2013). Air pollution and lung cancer incidence in 17 European cohorts: Prospective analyses from the European Study of Cohorts for Air Pollution Effects (ESCAPE). The Lancet Oncology. 14(9), pp. 813-822. https://doi.org/10.1016/S1470-2045(13)70279-1.

Somda D. D. (2018). Inventaire d'émissions de polluants atmosphériques issus du trafic routier à Ouagadougou (Burkina Faso). Mémoire de Master, IGEDD, Université Ouaga I Pr Joseph KI-ZERBO (Burkina Faso)

Tsai, M. Y. et al. (2015). Spatial variation of PM elemental composition between and within 20 European study areas - Results of the ESCAPE project. Environment International. 84, pp. 181-192. https://doi.org/10.1016/j.envint.2015.04.015

US EPA. (2011). Emission Factor Documentation for AP-42. Section 13.2.1. U.S. Environmental protection Agency. https://www.epa.gov/air-emissions-factorsand-quantification/ap-42-compilation-air-emissionsfactors 


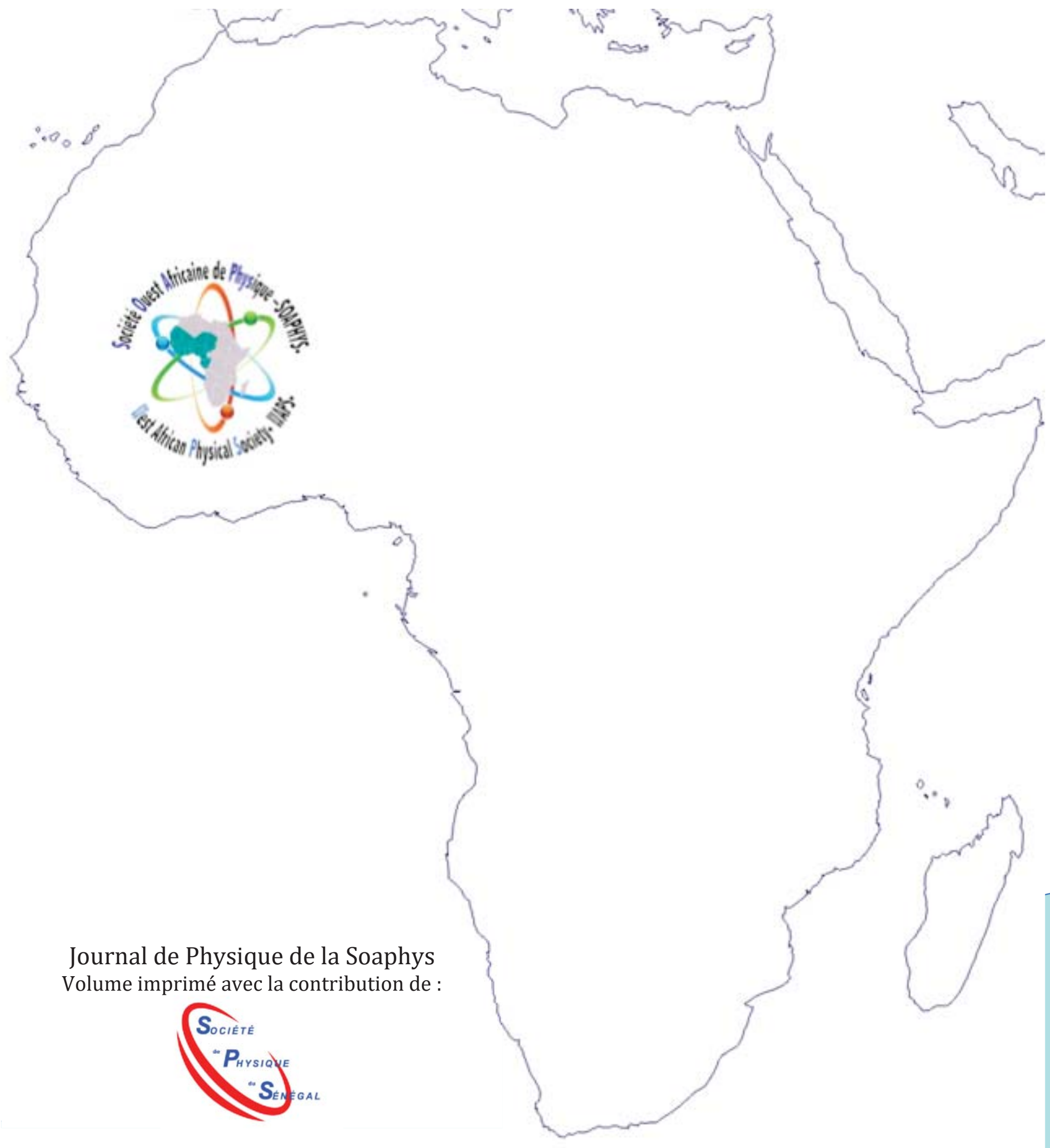

